\title{
IdeAs
}

Idées d'Amériques

Poètes et éditeurs : diffuser la poésie d'avant-garde américaine (depuis 1945)

\section{Michel Faucheux, Buffalo Bill}

Paris, Gallimard, 2017, 298 pages

\section{Nathalie Massip}

\section{OpenEdition}

\section{Journals}

Édition électronique

URL : https://journals.openedition.org/ideas/1927

DOI : $10.4000 /$ ideas. 1927

ISSN : $1950-5701$

\section{Éditeur}

Institut des Amériques

\section{Référence électronique}

Nathalie Massip, « Michel Faucheux, Buffalo Bill », IdeAs [En ligne], 9 | 2017, mis en ligne le 12 juillet 2017, consulté le 20 octobre 2022. URL : http://journals.openedition.org/ideas/1927 ; DOI : https:// doi.org/10.4000/ideas.1927

\section{Ce document a été généré automatiquement le 20 octobre 2022}

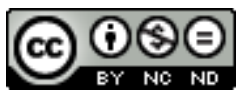

Creative Commons - Attribution - Pas d'Utilisation Commerciale - Pas de Modification 4.0 International - CC BY-NC-ND 4.0

https://creativecommons.org/licenses/by-nc-nd/4.0/ 


\title{
Michel Faucheux, Buffalo Bill
}

\author{
Paris, Gallimard, 2017, 298 pages
}

\author{
Nathalie Massip
}

\section{RÉFÉRENCE}

Michel Faucheux (Dir.), Buffalo Bill, Paris, Gallimard, 2017, 298 pages

1 Avec cet ouvrage, Michel Faucheux et les éditions Gallimard font le pari d'une nouvelle biographie de l'un des personnages les plus célèbres de l'Ouest américain: William Frederick Cody, alias Buffalo Bill. Publiée à l'occasion du centenaire de sa mort, cette étude retrace la vie de Cody, de sa naissance, en 1846, dans une jeune Amérique qui se construit mais est déjàau bord de la rupture, à sa mort, en 1917, au moment où les États-Unis entrent dans la Première Guerre mondiale.

Dès son enfance, Cody est exposé à la violence d'une nation qui se déchire sur la question de l'esclavage. Lorsque sa famille s'installe dans le Kansas, un territoire qui est le principal théâtre d'affrontements entre partisans de l'esclavage et abolitionnistes avant même la guerre de Sécession, elle devient la cible d'actes de violence, en raison des prises de position abolitionnistes du père de William. Le garçon n'a que onze ans lorsque celui-ci décède. Il doit alors concilier sa soif d'aventures avec ses responsabilités familiales: il observe la nature, chasse, et participe à des convois, notamment pour la compagnie Russell, Majors \& Waddell, qui créera, plus tard, le Pony Express. Ce sont ces périples, dont certains sont très dangereux, en raison des attaques d'Indiens, qui initieront le jeune garçon aux histoires racontées au coin du feu lors des bivouacs. Les conteurs d'histoire que sont les convoyeurs lui font une forte impression, au point que Faucheux se demande si certains, tel James Butler («Wild Bill») Hickok, une autre légende de l'Ouest, n'auraient pas joué le rôle de figure paternelle. Ces aventures ont donné à William le goût de la narration, qui l'accompagnera jusqu'à la fin de sa vie.

3 Chasseur de bisons, éclaireur, fondateur de villes (Rome, dont la brièveté de l'existence n'a d'égal que l'ambition démesurée affichée dans son nom, puis cody, dans le 
Wyoming), William Cody devient aussi chasseur d'Indiens lorsqu'il s'agit de venger le général Custer, tombé lors de la bataille de Little Bighorn, en 1876.Mais l'«Indien blanc " fut également acteur, dans des pièces de théâtre qui préfigurent les spectacles de Wild West. Véritables reconstitutions de l'épopée de la conquête de l'Ouest, ces derniers voient le jour en 1884, et connaîtront un immense succès pendant plus de trente ans, aux États-Unis comme en Europe. Soucieux des moindres détails, Cody met en scène de nombreux éléments symbolisant la frontière, des prouesses des cowboys aux attaques de diligences, en passant par des cyclones ou des destructions de campements de colons par des Indiens. Bien qu'une forte dose de fiction soit inhérente à ces spectacles, certaines affiches mettent en avant leur caractère didactique et réaliste, ${ }^{1}$ preuve de la capacité de Cody à « fabriquer l'illusion de la réalité » (58).

4 William Frederick Cody est, sous la plume de Faucheux, une figure contradictoire. Qualifié d'« homme-frontière " par le biographe, il représente tant l'Ouest sauvage que la modernisation de la nation. Véritable symbole de cet Ouest qui, déjà, oscille entre fiction et réalité, Cody incarne également l'ambiguïté d'une nation qui se métamorphose. Carles États-Unis se développent considérablement pendant le dixneuvième siècle et, plus particulièrement, pendant la période qui suit la guerre de Sécession. Entre la naissance de Cody, en 1846, dans le territoire de l'Iowa, et sa mort en 1917, pas moins de vingt États entrent dans l'Union. Non seulement la nation s'étend vers l'Ouest, au fil de l'expansion territoriale et de la transformation en États des territoires nouvellement acquis, mais elle s'industrialise et se modernise. De fait, plus encore que la vie bien remplie d'un personnage aux multiples aventures, l'on retiendra de Cody qu'il était profondément ancré dans son époque, au point d'en être devenu l'un des plus grands symboles.

5 Surtout, les États-Unis sont, au dix-neuvième siècle, une jeune nation qui a besoin de héros et de légendes. Cody l'a compris, et offre à l'Amérique une épopée digne des plus anciennes civilisations. Car celui qui deviendra «Buffalo Bill» ne doit sa renommée mondiale à nulle prouesse, si ce n'est celle d'avoir su construire lui-même sa propre légende, et de l'avoir diffusée à une très grande échelle, en utilisant tous les moyens qui s'offraient à lui : spectacles, livres (notamment les dime novels écrits par Ned Buntline mais, aussi, Prentiss Ingraham), photographies, affiches, films... L'ouvrage de Faucheux est d'ailleurs agrémenté de quelques portraits et photographies du héros de l'Ouest qui rappellent sa propension à sa propre théâtralisation. Le développement de média tels que la presse écrite et la littérature populaire, qui diffusent et popularisent le mythe Buffalo Bill, a lieu à un moment-charnière de l'histoire américaine, alors que l'Ouest sauvage disparaît et que la société se transforme. La toile de fond de la vie de Cody est un monde en mutation, marqué par le passage à l'âge adulte de la nation américaine.

6 L'entreprise de Faucheux s'expose à une double difficulté. D'une part, Buffalo Bill est tellement connu, et a fait l'objet de tant de récits, que l'on peut se demander s'il reste encore des éléments de sa vie qui n'ont pas été documentés. D'ailleurs, l'étude de Faucheux emprunte beaucoup à quatre biographies de Cody parues entre 1960 et 2005. D'autre part, si Cody lui-même a laissé un certain nombre de récits, la véracité de ces derniers est douteuse, ce qui rend leur utilisation particulièrement délicate dans le cadre d'une biographie. En effet, Cody est l'un des artisans, si ce n'est le principal auteur, de son propre mythe. Autrement dit, ses écrits autobiographiques sont plus précieux pour ce qu'ils révèlent de la société de son époque et de la naissance d'un mythe que pour ce qu'ils nous apprennent de la vie du personnage. C'est ce que nous 
fait comprendre Michel Faucheux, en montrant bien l'ambivalence de William F. «Buffalo Bill» Cody, qui incarne tout autant qu'il façonne l'ambiguïté du monde qui l'entoure, entre rêve et réalité, mythe et fiction, modernité et traditionalisme mais, aussi, spectacle et vie réelle.

\section{NOTES}

1. Une de ces affiches indique ainsi : "It is not a 'show' in any sense of the word, but it is a series of original, genuine and instructive object lessons in which the participants repeat the heroic parts they have played in actual life upon the plains, in the wilderness, mountain fastness and in the dread and dangerous scenes of savage and cruel warfare." Cité dans Richard slotkin, Gunfighter Nation.The Myth of the Frontier in Twentieth-Century America.Norman: University of Oklahoma Press, $1992 ; 82$.

\section{AUTEURS}

\section{NATHALIE MASSIP}

MCF études américaines, Université Nice Sophia Antipolis, membre de l'Université Côte d'Azur (UCA) 